\title{
INNOVATION TRENDS IN E-COMMERCE APPLICATIONS: GITTIGIDIYOR.COM CASE
}

\author{
DOI:10.17261/Pressacademia.2019.1091 \\ PAP- V.9-2019(38)-p.192-196
}

\section{Demokaan Demirel ${ }^{1}$, Vedat Eris ${ }^{2}$}

${ }^{1}$ Kocaeli University, Department of Politics and Public Finance, Kocaeli, Turkey demokaan.demirel@kocaeli.edu.tr, ORCID: 0000-0001-5454-9507

${ }^{2}$ Kocaeli Üniversitesi, Institute of Social Sciences, Kocaeli, Turkey eris vedat@hotmail.com ,ORCID: 0000-0002-8196-9504

To cite this document

Demirel, D., Eris, V., (2019). Innovation trends in e-commerce applications: gittigidiyor.com case. PressAcademia Procedia (PAP), V.9, p.192196

Permemant link to this document: http://doi.org/10.17261/Pressacademia.2019.1091

Copyright: Published by PressAcademia and limited licenced re-use rights only.

\section{ABSTRACT}

Purpose- Nowadays, with the increasing competition, new products and services, which make life easier in the field of entrepreneurship and trade, emerge. Especially as a result of digitalization, producers and consumers have been able to meet on a new platform. The virtual shopping platforms, in which time and space concepts have lost their meaning, have many advantages. As an alternative to physical stores, there has been a significant increase in e-commerce applications with the combination of change in marketing concept and technological innovations. E-commerce is increasingly replacing traditional trade. Innovation trends in e-commerce also brought different applications in the sector. For example; important applications such as various payment options, mobile commerce and improved delivery and hire-purchase options have brought vitality to the e-commerce industries. As in the globalizing world, e-commerce in Turkey has started to come to the fore in the recent years and various virtual commercial formations have emerged.

Methodology- The study is based on empirical findings ragarding e-commerce applications and interprets innovation evaluations according to the practices on gittigidiyor.com

Findings- E-commerce applications get momentum on a global scale. Together with different innovation techniques, e-commerce applications provide superiority to organizations in technological competition.

Conclusion- In our study, these formations which are the result of digitalization are discussed and the tendency of innovation in e-commerce applications will be tried to be evaluated in the context of Gittigidiyor.com case.
\end{abstract}

Keywords: E-commerce, innovation, information and communication technologies, gittigidiyor.com. JEL Codes: O3, O31, O33

\section{E-TiCARET UYGULAMALARINDA INOVASYON EĞiLIMLERI: GITTIGIDIYOR.COM ÖRNEĞi}

\section{ÖZET}

Amaç- Günümüzde artan rekabet ile birlikte girişimcilik ve ticaret alanında hayatı kolaylaştıran yeni ürün ve hizmetler karşımıza çıkmaktadır. Özellikle dijitalleşme sonucunda üreticiler ve tüketiciler yeni bir platformda buluşma imkânına kavuşmuştur. Zaman ve mekân kavramlarının anlamını kaybettiği sanal alışveriş platformları birçok avantajlara sahiptir. Pazarlama anlayışındaki değişim ve teknolojik yeniliklerin birleşimiyle fiziksel mağazalara alternatif olarak e-ticaret uygulamalarında önemli bir artış meydana gelmiştir. E-ticaret giderek geleneksel ticaretin yerini almaktadır. E-ticaretteki inovasyon eğilimleri de sektörde farklı uygulamaları beraberinde getirmiştir. Örneğin; çeşitli ödeme seçenekleri, mobil ticaret ve geliştirilmiş teslimat ve taksit seçenekleri gibi önemli uygulamalar e-ticaret sektörüne canlılık kazandırmıştır. Yöntem- Çalışma e-ticaret uygulamalarına ilişkin ampirik bulguları esas almaktadır ve inovasyon değerlendirmelerini gittigidiyor.com sitesi üzerindeki uygulamalara göre yorumlamaktadır.

Bulgular- E-ticaret uygulamalarının küresel çapta ivme kazandığı görülmektedir. E-ticaret uygulamaları inovasyon teknikleriyle birlikte teknolojik rekabette örgütlere üstünlük sağlamaktadır.

Sonuç- Küreselleşen dünyada olduğu gibi Türkiye'de de e-ticaret son dönemde ön plana çıkmaya başlamıştır ve çeşitli sanal ticari oluşumlar ortaya çıkmıştır. Çalışmamızda dijitalleşmenin bir sonucu olan bu oluşumlar ele alınmaktadır ve Gittigidiyor.com örneğinde e-ticaret uygulamalarındaki inovasyon eğilimleri değerlendirilmeye çalışılmaktadır.

Anahtar Kelimeler: E-ticaret, inovasyon, bilgi ve iletişim teknolojileri, gittigidiyor.com. JEL Kodu: O3, O31, 033 


\section{GiRiş}

E-ticaret günümüzde ticaret kavramının değişmesine katkıda bulunan bir ticaret türüdür. E-ticaret aracıllı̆ıyla sanal ortam üzerinden alışveriş yapma olanağı gitgide artmaktadır. E-ticaretin mal ve sermaye akışlarının ülkeler arasında serbestçe gerçekleşmesini ifade eden ekonomik küreselleşmeyle ülkeler açısından da önemli bir süreç haline geldiğini vurgulamak gerekir. Elektronik ortamda ticaret yapma imkânı sunan yeni ve güncel bu kavram beraberinde çeşitli soru işaretlerini ve riskleri de getirmektedir. Aynı zamanda bu kavram yenilikçilik diye tasvir edebileceğimiz inovasyon kavramı ile de yakın ilişki içerisindedir. İnovasyon bilgi çağının gerekliliklerine uygun olarak şirketlerin iş yapış tarzını verimlilik ve etkinlik ilkeleri temelinde değiştirmiştir. Bu kapsamda çalışmanın temel amacı, e-ticaret ve inovasyon eğilimleri arasında bir bağlantı kurarak somut örnek kapsamında ilişkisel bir analiz yapmaktır. Çalışmanın temel problemi e-ticaret uygulamaları üzerinde inovasyon kavramının getirdiği değişimin etkilerini tespit etmektir. Bu kapsamda çalışmada yenilikçi hareketlerin sanal ortamdaki ticari faaliyetlere etkileri kavramsal açıklama ve tartışma çeşitli örnekler vasıtasıyla örneklendirilmektedir ve konunun günümüzdeki anlamı tartışılmaktadır. Daha sonra ise günümüzde Türkiye'de faaliyet gösteren Gittigidiyor.com oluşumu ele alınarak e-ticaret alanına yapmış olduğu katkılardan söz edilecektir. Bu tartışma yürütülürken söz konusu oluşumun tarihsel süreçte teknolojik anlamda getirmiş olduğu yenilikler incelenecek ve bunun e-ticaret alanına yapmış olduğu katkılardan söz edilecektir.

\section{E-TICARET KAVRAMI}

E-ticaret kavramı küreselleşme ile birlikte hayatımızda yer almaya başlayan önemli kavramlar arasındadır. Ticarette geleneksel kalıpların yavaş yavaş yıkılmaya başladığı bu dönemde e-ticaret konusuna ayrı bir başık açmak gerekmektedir. Çünkü artık geleneksel ticaretin boyut değiştirdiği, alıcı ve satııı başta olmak üzere diğer tüm aktörlerin bir araya gelebildiği farklı platformların karşımıza çıktığını görüyoruz. Yüz yüze veya fiziki mekânlarda gerçekleşen ticaret günümüzde internet ortamına taşınmış ve bu bir dönüşümü de beraberinde getirmiştir. Bu anlamda e-ticaret konusu ticaret anlayışının geçirmiş olduğu bu dönüşümü açıklamak ve anlamak açısından önemli görülmektedir.

E-ticaretin çeşitli şekilde tanımlarına rastlamak mümkündür. Burada esas olarak örnek vereceğimiz üç önemli kurumun yaklaşımı olacaktır. Söz konusu kuruluşlar Dünya Ticaret Örgütü, i̇ktisadi Kalkınma Teşkilatı ve Avrupa Komisyonu’dur. Dünya Ticaret Örgütü, e-ticaret kavramını mal ve hizmetlerin üretim, reklam, satış ve dağııımlarının telekomünikasyon ağları üzerinden yapılması ve ticaretin bu platforma taşınması şeklinde ele almaktadır. İktisadi Kalkınma Teşkilatı konuyu farklı bir açıdan inceleyerek e-ticareti, ticari faaliyetlerin metin, ses ve görsel imajları kapsayan dijital verilerin aktarımı biçiminde gerçekleşmesi şeklinde tanımlamıştır. Avrupa Komisyonu ise, konuya işletme açısından yaklaşarak e-ticareti, işletmelerin faaliyetlerini elektronik olarak bu platformda gerçekleştirmesi seklinde ele almıştı (Canpolat, 2001: 11-26). Esasen bu üç tanımdan da hareketle belirtilmesi gereken nokta e-ticaretin geleneksel usuller dışında farklı bir ortamda (elektronik) gerçekleştirildiğidir. Diğer geleneksel ticaret yöntemlerinden ayrıldığı nokta tam da burasıdır.

E-ticaretin tanımlamasından hareket ederek söz konusu ticarette kullanılan araçların farklılaştı̆ı belirtilebilir. Bu yeni ticaret modelinde telefon, faks, elektronik veri değişimi, televizyon, bilgisayar, internet, elektronik ödeme gibi birçok araç kullanılmaktadır. Buradan da çok aktörlü bir süreç karşımıza çıkmaktadır. Çok fazla aracın kullanıldığı e-ticaretin tarafları da doğal alarak farklılaşacak ve çoğalacaktır. E-ticaretin tarafları ise, başta alııılar ve satıcılar olmak üzere, üreticiler, imalatçılar, sigorta şirketleri, komisyoncular, özel sektör bilgi teknolojileri, üniversiteler, sivil toplum kuruluşları, nakliye şirketleri, elektronik noterler, ilgili bakanlıklar ve diğer kamu kurum ve kuruluşları olmak üzere oldukça çeşitlidir (Canpolat, 2001: 11-26). Çok aktörlü bu süreç gerekli yasal ve idari düzenlemeleri yapma ihtiyacını da ortaya çıkaracaktır. Bu anlamda kamu kurum ve kuruluşları da süreçte aktif olarak rol almaktadır. Sınırları belli olmayan bir süreç olmasından dolayı e-ticaret, sürekli olarak denetlenmesi ve kurallarının belirlenmesi gereken bir olgu olarak karşımıza çıkacaktır. Bu anlamda sürecin aktörleri gün geçtikçe çoğalabilecektir. Bu bakımdan kamu yönetiminin e-ticaret işlemlerine ilişkin usul ve esasları ortaya koyması, e-ticaretin gerçekleşmesi sürecinde tarafların karşılıkı hak ve menfaatlerini gözetmesi, güvenliğe ilişkin çeşitli önlemlerin alınarak tarafların mağdur edilmemesine gayret göstermesi önemli bir gerekliliktir.

E-ticaret yükselen hacmi ile birlikte ticaret alanında önemli bir yer edinmeye başlamıştır. Bu alan kendi içerisinde birçok olumlu ve olumsuz öğeyi barındırmaktadır. Öncelikle, e-ticaret alıcı ve satııılar arasında ara yüzler aracılı̆ıyla elektronik iletişimi artıırmaktadır. Bunun yanında zamanın etkin kullanımını sağlamakta, zaman kaybının önüne geçebilmektedir. Kırtasiyeciliği azaltmak noktasında da faydalı olmaktadır. Müşterilere yönelik interaktif etkileşim sayesinde müşterilerin talepleri veya sorunları kolaylıkla takip edilebilmekte ve bu gelişmeler ışı̆̆ında müşteri iletişim merkezleri aracılığıyla hızlı çözüm veya yanıt üretilebilmektedir. E-ticaret ticari işletmelerin işlem maliyetlerinin düşmesine yardımcı olmaktadır. Örneğin; nakliye ücretleri düşebilmektedir. E-ticaret bir başka yönü ile çok sayıda tüketici ve üreticinin küresel piyasaya entegre olmasına yardımcı olmaktadır. Bu anlamda özellikle yeni tüketici memnuniyeti deneyimi ve iş gücü profillerinin doğmasına yardımcı olmaktadır. Bu sektör ile birlikte geleneksellikten uzaklaşılmakta ve uzmanlaşma daha da ön plana çıkmaktadır (Canpolat, 2001: 11-26). Uzmanlaşmanın artması ile birlikte çeşitli reklam, mobil uygulama vb. çalışmalar ile e-ticaret sektörü canlanmaktadır. Bu canlıık beraberinde yeni iş alanlarının doğmasına yardımcı olmaktadır. Müşteriler açısından ürün ve hizmetlere ulaşabilme fırsatlarını beraberinde getirmektedir.

E-ticaret bir yönüyle de herkese eşit erişim imkânı sağlamaktadır. Örneğin, bir internet sitesinden satış yapan firmanın ürünlerine internet kullanııısı olan herkes erişebilir. Aynı şekilde e-ticaret sistemine entegre olarak satış yapmak isteyen bir kişi veya kurum çeşitli prosedürleri yerine getirdiği takdirde rahatlıkla satış yapabilecektir. Bunların yanında bilgiye erişim de kolaylaşmaktadır. Sisteme girilen bilgiler bir diğer işlemde tekrar sisteme girilmek zorunda değildir. E-ticaret sektöründe alıcı ve satııının birebir görüşmesi gerekmemekte ve alım-satım işlemi birebir görüşme olmadan da gerçekleşebilmektedir. Başka bir yönüyle e-ticarette bilgilerin hızlı iletimi söz konusu olurken, alıııların evlerine kadar hizmet götürülebilmektedir. Ayrıca e-ticarette ürün yelpazesinin çok geniş olması, ürün ve hizmet kataloglarında gerçekleştirilen promosyonların yaygınlığı bu ticaret biçimini daha da cazip kılmaktadır (Aydın ve Sarısakal, 2003: 84).

Özellikle önceki dönemlere ilişkin ticaret hacminde artışa genellikle büyük ölçekli işletmelerin ulaştı̆̆ı söylenebilmektedir, fakat e-ticaret ile birlikte küçük ve orta ölçekli işletme ve girişimlerin de dünya pazarına açılması ve bu pazardan pay almasının yolu açılmış olmaktadır. Bu anlamda e-ticaretin küçük işletmeler ve girişimciler için de piyasada bir oyuncu olarak yer almak bakımından fırsat yarattığı belirtilebilir (Bakırtaş ve Tekinşen, 2006: 12). Ancak, söz konusu bu küçük ve orta ölçekli işletmelerin e-ticaretin kendileri için yaratmış oldukları faydanın 
tam anlamı ile farkında olmamaları, teknolojik yetersizlikler ve yetişmiş eleman eksikliği sıkıntısından dolayı sürece etkin bir şekilde katılımları söz konusu olamamaktadır (Kalaycl, 2008: 147).

Her ticaret kolunda olduğu gibi e-ticaretin de faydalarının yanında bazı olumsuz yönleri bulunmaktadır. Öncelikle e-ticaret ülkeler arasındaki refah düzeyi farklılıklarını arttırmaktadır. Örneğin; uluslararası anlamda faaliyet gösteren bir e-ticaret devi şirkete sahip olan bir ülke ekonomisi, diğer ülke ekonomilerine oranla daha fazla katma değer yaratmaktadır. Bir başka yönüyle, e-ticaret yeni iş kollarının gelişmesine katkıda bulunsa da ekonomide iş gücü fazlası yaratarak işsizliğin artmasına neden olabilecek bir potansiyele de sahiptir. E-ticaret ile birlikte eğitimli beyaz yakalı işgücüne olan gereksinim artmaktadır. Bu durum işletmeler açısından niteliksiz işgücü istihdamını oldukça daraltmaktadır. Çok geniş bir alana yayılmış olması ve elektronik ortamda hizmet veriyor olmasından dolayı e-ticaret, tam anlamıyla kamu kesimi tarafından denetlenebilir bir alan değildir. Denetimin oldukça güç olması ve çeşitli problemler ile karşılaşılabilme potansiyeli taşıyor olması e-ticaretin olumsuz yönleri arasında sayılabilir (Canpolat, 2011: 11-26). Bir diğer dezavantaj e-ticaretin bir tekelleşme tehlikesine sahip olması ve ödeme sistemleri açısından eksik rekabet yaratabileceği gerçeğidir (Aytekin ve Dikkaya, 2018: 76). Ayrıca, işlemler yapılırken korsan siber saldırı tehlikesinin bulunması, tanınmamış veya sahte şirketlerin bulunması, aldatıcı reklamların konması, ürünü görememe ve ürünün kaybolma riskinin de varlığını koruması gibi durumları bünyesinde barındırması nedeniyle e-ticarete ilginin azalabileceği ileri sürülmektedir (Pırnar, 2005: 16).

\section{INOVASYON KAVRAMI VE E-TICARET}

İnovasyon köken itibari ile yeni bir uygulama biçimini ifade etmektedir. İnovasyon kültürel ve idari ortam söz konusu olduğunda işletme süreçlerinde, mal ve hizmetlerin üretilmesinde, pazarlanmasında, tüketicilere sunulmasında yeni yöntemlerin kullanılmaya başlanması anlamını taşımaktadır (Elçi ve Karataylı, 2008: 1). Yalın yönetim uygulamalarının yaygınlaşmasıyla birlikte işletmeler açısından yeni ve farklı bir sonuçlara elde etmeye yönelik inovasyon girişimleri artmıştır. Basit tabirle inovasyon ortaya çıkan bir sorunun (problemin) çözümü noktasında ortaya çıkabilecek sorulara verilebilecek yanıtlardır (Akyos, 2007: 6). Kurumsal açıdan her türlü işletme fonksiyonunda karşımıza çıkabilecek yenilikçi yaklaşımlardır. Geleneksel çözümlerin ötesine geçilerek üretilebilecek radikal çözüm önerileri de bu kapsamda değerlendirilebilir. İnovasyon çoğu zaman yeni bir ürünün piyasaya sürülmesi şeklinde karşımıza çıkabilirken, çoğu zaman da değiştirilmiş, dönüştürülmüş şekilde bir ürünün piyasaya farklılaştırılmış bir tarzda ve yapıda sürülmesi şeklinde karşımıza çıkmaktadır. Kısacası, inovasyon tamamıyla yeniden üretimi değil, aynı zamanda üretilmiş olanın niteliğinin değiştirilmesi, niteliğin daha da arttırılmasına ve ürün hatalarının minimuma indirilmesine yönelik çabalar şeklinde de karşımıza çıkabilmektedir.

E-ticaret söz konusu olduğunda inovasyon kavramı bir kez daha kendisini hissettirmektedir. Çünkü e-ticaret sektörü de yeni buluşların veya değiştirilmiş, dönüştürülmüş ürünlerin kendisine sunum imkânı bulduğu bir platformdur. Dolayısı ile inovasyon eğilimleri ile desteklenmiş bir e-ticaret adımının başarıya ulaşması daha kolay olacaktır. Ürün yelpazesinin oldukça genişlediği bir e-ticaret sektörü düşünüldüğünde belirli bir kişiye, gruba, topluma veya topluluğa yönelik yenilikçi uygulamalar geliştirme ihtiyacı çok daha fazla hissedilmektedir. İnternetin çağımızda oldukça yaygınlaşması ile birlikte e-ticarette de yenilikçi fikirler ve uygulamalar geliştirmek ihtiyacı doğmuş, sosyal medyanın hayatımıza girişi ile birlikte bu ihtiyaç daha da derinleşmiştir. Tüketicilerin günümüzde bilinç düzeyinin arttığı ve daha seçici oldukları göz önünde bulundurulduğunda kişilere özel içerik üretme zorunluğunun doğması kaçınılmazdır. Bu kapsamda kitlesel özelleştirme (mass customization) kavramına vurgu yapılmaktadır ve ürünlerin üretim safhasında müşterilerin bireysel tercihleri ve beklentileri dikkate alınmaktadır. Bu yönde e-ticaret devleri de çeşitli inovatif faaliyetlerde bulunarak pazar paylarını arttırmaya çalışmaktadırlar. Bu e-ticaret devleri farklılaşma ve farklılaşmanın getireceği talep için yoğun mesai harcamanın yanında belirli bir maliyete de katlanmaktadırlar.

Dünyada ve Türkiye'de e-ticaret söz konusu olduğunda çeşitli büyük oluşumlar karşımıza çıkmaktadır. Dünyada e-ticaret sektöründe Amazon (ABD), Ebay (ABD), Alibaba (Çin) gibi önemli şirketler söz sahibi olmaktadır. Türkiye'de ise Hepsiburada.com 1998, Gittigidiyor.com 2001 yılında kurulmuştur. Türkiye' de e-ticaret 2008 sonrası dönemde gelişim göstermiştir. Sahibinden.com 1999, Yemeksepeti.com 2001, Trendyol 2010 ve N11.com 2013 yılında kurularak e-ticaretin gelişimine katkıda bulunmuşlardır. Türkiye'de e-ticaret hacmi bütün bu gelişmeler ışığında 2016 yılı itibariyle 30,8 milyar liraya ulaşmıştır. Söz konusu oran 2018'de \%42'lik bir büyüme ile 59,9 milyar liraya çıkmıştır (www.digitalage.com.tr) Dünyada ise e-ticaret hacmi 2016 yılı itibariyle 1.607 trilyon dolara ulaşmıştır. 2018 itibarı ile dünya e-ticaret hacmi ise 700 milyar doları geçmiştir, fakat bu pastadan gelişmiş ülkeler gelişmekte olan ülkelere oranla çok daha fazla pay almaktadır (Aytekin ve Dikkaya, 2018: 79-83; www.hurriyet.com.tr). E-ticaret cari açığı yüksek ülkeler bakımından ödemeler dengesini rahatlatabilecek önemli rekabet araçlarından biri haline gelmiştir.

Dünya'da ve Türkiye'de önemli bir pazar alanı haline gelen e-ticaret kuşkusuz inovasyon eğilimlerinin de artmasıyla önemli gelişmeler göstermiştir. Son dönemde ödeme sistemlerinde meydana gelen değişimler bu sektörü daha da cazip hale getirmiştir. Mobil uygulamalara yönelimin artması ve internetin artık mobil telefonlar aracılığı ile daha aktif kullanılır hale gelmesiyle birlikte fiziki mekânlardan ziyade eticarete yönelim artmıştır. Ödeme sistemlerinin genişlemesinin yanı sıra kargo seçeneklerinin de çeşitlenmesi bu anlamdaki inovatif faaliyetlerin artması neticesinde e-ticaret hacminde gelişmeler yaşanmaktadır. Örneğin; Türkiye'deki bir vatandaş Çin'deki bir e-ticarette aktif bir oluşumdan alışveriş yaptığında ürününü sorunsuz şekilde adresinde teslim alabilmektedir. Bu örnek dahi e-ticaret sisteminin geldiği noktayı göstermesi açısından önemlidir. İnovasyon eğilimlerinin artması ve yenilikçi faaliyetler sonucunda ortaya çıkan değişimler kuskusuz e-ticaret sisteminin gelişmesine katkıda bulunacaktır.

Günümüzde e-ticaret alanında uygulamaya geçirilen inovatif uygulamalara örnek vermekte fayda vardır. Çünkü bu faaliyetler ve yenilikler sektöre canlııık kazandırmakta ve sektörün geleceği açısından fikir sahibi olmamızı sağlamaktadır. Örneğin; İsviçre'den Digitec Galaxus 2019 yılında kripto para kullanımını gündemine alarak alternatif ödeme sistemlerini genişletmiştir. Bir başka örnek olarak Instagram alışveriş özelliğini ödeme sistemini de bünyesine entegre ederek 2019 yılında genişletmiştir. Böylece sosyal ağdan çıkış yapmadan ödeme kolaylığı sağlanmış olacaktır. Bir diğer örnekte Evida.com'un ilk fiziksel mağazasını 2016 yılında açtığına şahit oluyoruz. Bir e-ticaret platformu olan Evidea.com tersine bir akımla e-ticaret ile başlayan serüvenine fiziksel bir mağaza eklemiştir. Bir başka örnekte Amazon'un Amazon Go uygulaması ile al ve çık mottosuyla 2016 yılında test ettiği dijital sistemle kasiyerlerin işlerine son verecek bir uygulama geliştirmiştir. 
Müşteriler mağazada istediklerini alacak ve daha sonra fatura müşterilerin mobil cihazlarına gelecektir (www.inovaloji.com, 24.06.2019). Son Amazon örneğinde de görüleceği üzere dünyada ve Türkiye'de e-ticaret sektöründe inovasyon eğilimlerinin artması ile birlikte ortaya çıkan yenilikçi faaliyetler bir yandan ekonomiye yeni bir boyut kazandııırken, iş gücünün yapısal niteliğine de doğrudan etki edebilmektedir. Bu yönüyle e-ticaretin yaygınlık kazanması ülke ekonomisi üzerinde çok boyutlu etkilerde bulunabilmektedir.

\section{E-TiCARETTE INOVASYON VE GITTIGIDIYOR.COM ÖRNEĞi}

E-ticarette inovasyon oldukça önemli bir kavramdır. Yenilikçi faaliyetler ve buluşlar sektör temsilcilerine farklı ve rekabetçi bir görünüm kazandırdı̆̆ından işletmelerin pazar paylarını etkileyen önemli bir faktör olarak karşımıza çıkmaktadır. Aynı şekilde Türkiye'de de e-ticaret sektöründe önemli bir oluşum olan Gittigidiyor.com'un çalışmamız özelinde incelenmesi ve bu oluşumun mevcut durumunun inovasyon eğilimleri çerçevesinde değerlendirilmesi önemli görülmektedir.

Gittigidiyor.com 2001 yılında kurulmuştur. Kuruluşunun ardından 2011 yılında EBAY çatısı altına girmiştir. 2001 yılından bu yana faaliyet gösteren oluşum 50 kategoride 15 milyon ürün çeşitliliği ile müşterilerine hizmet vermektedir. Sıfır risk sisteminin hâkim olduğu internet sitesinde saniyede 1 ürün satışı gerçekleştirilmektedir. Fiziksel bir mağazada saniyede 1 ürün satışı gerçekleştirmenin zorluğu düşünüldüğünde e-ticaret sisteminin geldiği nokta daha rahat anlaşılacaktır. Gittigidiyor.com'un mobil uygulaması kullanıcılarca 9 milyon kez indirilmiştir. 204 çalışanı bulunan oluşumun 25 milyona yakın kayıtlı kullanıcısı bulunmaktadır (www.gittigidiyor.com, 24.06.2019). Rakamların da bize anlattığından yola çıkarak 25 milyona yakın kayıtlı kullanıcı olması oluşumun ulaşabildiği kişi sayısını göstermesi açısından önemlidir. Aynı zamanda yenilikçi yaklaşımla geliştirilmiş mobil uygulaması ile 9 milyon kullanıcıya ulaşması inovasyonun e-ticarette sahip olduğu öneme vurgu yapması açısından önemli görülmektedir.

Gittigidiyor.com oluşumundan söz edilirken bazı önemli tarihlerden ve bu tarihteki inovatif eğilimlerden söz etmek gerekir. 2001 yılında kurulan oluşum Temmuz 2001'de sıfır risk sistemi ile alışverişe başlamıştır. Nisan 2002'de hemen al opsiyonunu devreye koyan site yenilikçi bir adım atmıştır. Kasım 2005'te ilk televizyon reklamını veren oluşum, e-ticarette önemli bir kanal olan televizyonu da etkin bir şekilde kullanmaya başlamıştır. Mayıs 2009'da mobil yayınını devreye alan oluşum farklı bir platformla daha tanışmıştır. Aralık 2009'da Gittigidyor.com blog yayınına başlamıştır. Söz konusu oluşum Ekim 2010 itibariyle direkt uçuş imkânı sunmaya başlamıştır. Nisan 2011'e gelindiğinde inovasyon çalışmaları sonucu akıllı sıralama özelliği aktifleştirilmiştir. Ağustos 2011'de 3D teknolojisi aktif hale getirilmiş ve Ekim 2011'de banka kartları ile ödeme dönemi başlamıştır. Kasım 2012'ye gelindiğinde ise sanal ortam üzerindeki alışveriş farklı bir boyuta taşınmış ve kayıtlı olmayan müşterilerin de ürün alabilmesini sağlayan sistem geliştirilmiştir. Haziran 2014'e gelindiğinde sosyal ağların hayatımızda aktif olarak rol almasının bir sonucu olarak söz konusu oluşuma Facebook üzerinden de erişim imkânı sağlanmıştır (wwww.gittigidiyor.com, 24.06.2019). Bütün bu süreçten de görüleceği üzere Gittigidiyor.com teknolojik gelişmeler ışığında çağın gereklerine uygun olarak inovasyon eğilimlerini de göz önünde bulundurarak sürekli gelişim gösterme çabası içerisinde olan bir oluşumdur.

Gittigidiyor.com söz konusu olduğunda bazı temel uygulamalarından da söz ederek inovatif faaliyetlerini ayrıntılandırmak mümkündür. Örneğin; söz konusu oluşum müşterilerine 14 gün içerisinde ürün iadesi imkânı sunmaktadır. Satıcı, ürünü iade aldığı anda ürün bedeli alıcıya geri ödenmektedir. Kullanıcılar ürün takibini ürün sayfasından gerçekleştirebilmekte, kargo tarihinden itibaren 3 gün içerisinde ödeme onayı verebilmektedir. Ödeme onayı olmadan site ödemeyi satıcıya yapmamaktadır. Bu durum alıcılara ödeme güvenliği sağlayan bir husus olarak karşımıza çıkmaktadır. Aynı zamanda alıcılar satıcılar ile hem satış öncesi hem satış sonrası iletişime geçebilmektedir. Satıcı ve alıcı arasındaki karşııkı iletişimi önemseyen oluşum, başarılı ve çok başarılı satıcı değerlendirmelerini alıcıların kullanımına sunmaktadır. Başarısız olan satıcılar için de ilaveten bir telafi süreci öngörülmektedir. Ödeme söz konusu olduğunda ise oluşum; bankamatik ve kredi kartları, sanal kredi kartları, alışveriş kredisi, BKM Express, Garanti Pay, kayıtlı kart ile ödeme kolaylığı, Bonus, Worldpuan, Axess puan kullanımı gibi seçenekleri müşterilerinin deneyimine sunarken kapıda ödeme seçeneğini ise güvenlik gerekçesi ile kullanmamaktadır. Sıfır risk sistemi ile ödemeyi güvence altına alan oluşum, Thafte SSL sertifikasıyla kart bilgilerini şifrelemekte ve 3D secure güvenlik sistemini kullanmaktadır (www.gittigidiyor.com, 24.06.2019). Bütün bu çalışmalardan hareketle Gittigidiyor.com'un çağın gereklerine uygun olarak sanal bir organizasyon olarak çeşitli çalışmalar yaptığı ve inovasyon eğilimleri ile müşteri yelpazesini e-ticari uygulamalarını daha da müşteri odaklı kılmaya çalışarak genişlettiği görülmektedir. Sektörde kalıcı olmak adına bu tür çalışmalara devam etmesinin gerekliliği ise tartışılmazdır.

\section{SONUÇ VE ÖNERILER}

E-ticaret kavramı küreselleşme ile birlikte hayatımızdaki yeri daha da belirginleşen, ticaretin elektronik ortama taşınması anlamı taşıyan bir kavramdır. Bilgi toplumuna geçişe birlikte sanal organizasyon kavramının gelişmesi e-ticaretin yaygınlık kazanmasındaki önemli sebeplerden biridir. Dünya'da ve Türkiye'de önemini gittikçe artıran bu kavram bazı olumlu ve olumsuz yönleri bünyesinde barındırmaktadır. Özetle, çok fazla ürün çeşidini bünyesinde barındırması, maliyet ve zaman tasarrufu sağlaması bu ticaret türünün olumlu yönleri arasında sayılabilirken, ülkeler arası gelir dağılımında adaletsizlikler yaratması ve ulusal kamu yönetimlerince denetlenmesi zor bir alan olması bu ticaret türünün olumsuz yönleri arasında sıralanabilir.

E-ticaret söz konusu olduğunda bu kavramı inovasyondan ayrı düşünmek ise olanaksızdır. Faaliyet gösterilen sektörel alanlar da varlık gösterebilmek için yenilikçilik anlamı taşıyan inovasyona ayrı bir önem gösterilmesi zorunluluğu açık bir gerçek seklinde karşımıza çıkmaktadır. Yeni bir ürünün piyasaya sürülmesi, bir ürünün farklı bir şekilde sunulması veya üretim yöntemlerindeki değişiklik ile birlikte hata oranlarının minimuma çekilmesi, müşteri memnuniyetinin sağlanması açısından örgütsel bir değer yaratacak ve örgütün rakipleri arasında fark yaratmasına katkıda bulunacaktır.

E-ticaret ve inovasyon kavramlarının irdelenmesinin ardından bu iki kavramın da birbiriyle neden-sonuç ilişkisi içinde bulunduğu söylenebilir. İşletme süreçlerindeki inovasyonlar e-ticaret hacminde de olumlu yönde sonuçlar doğurmaktadır. Buradan hareketle inovasyon eğilimlerinin kendisini hissettirdiği sektörlerden biri olan e-ticarette Türkiye'de faaliyet gösteren Gittigidiyor.com örneği üzerinden yaptığımız değerlendirmeden de göreceğimiz üzere yenilikçi hareketler e-ticarette faaliyet gösteren firmaların kendilerini geliştirmeleri ve piyasada tutunabilmeleri açısından hayati öneme sahiptir. Yapılacak yatırımlar ile sürekli olarak yenilikçi faaliyetlerde bulunmak firmanın ömrünü 
uzatacaktır ve tanınırlğını arttıracaktır. Müşteriler açısından da firmanın güvenirlik kapasitesini geliştirecektir. Bu durum aynı zamanda ülke ekonomisine de doğrudan olumlu etki edecektir. E-ticaret sektöründe faaliyet gösteren oluşumlar bünyelerinde kuracakları teknoloji birimleri ile yeni içerikler üretebilme imkânına da sahip olacaklardır.

\section{KAYNAKÇA}

Akyos, M. (2007). Kamuda İnovasyon. http://www.inovasyon.org/pdf/MA.Kamuda.Inovasyon.pdf, (ET: 24.06.2019).

Aydın, M. A., Sarısakal, M. N. (2003). E-Ticaretin Yeni Yüzü Mobil Ticaret. Havacılık ve Uzay Teknolojileri Dergisi, 1 (2), s. 83-90.

Aytekin, i., Dikkaya, M. (2018). Küresel E-ticaret ve Türkiye. JEBPIR, 4 (1-2), s. 66-88.

Bakırtaş, H., Tekinşen, A. (2006). E-ticaretin Girişimcilik Üzerine Etkileri. Selçuk Üniversitesi, Sosyal Bilimler Enstitüsü Dergisi, 16, s. 125-138.

Canpolat, Ö. (2001). E-ticaret ve Türkiye'deki Gelişmeler. Türkiye Cumhuriyeti Sanayi ve Ticaret Bakanlığı Hukuk Müşavirliği, http://my.beykoz.edu.tr/serkang/files/2010/12/e-ticaret-ve-Turkiye.pdf, (ET: 24.06.2019).

Digital Age. Türkiye'nin e-ticaret hacmi 59,9 milyar TL'ye ulaştı. www.digitalage.com.tr/turkiyede-e-ticaret-hacmi-599milyar-tlyeulasti/amp/, (ET: 26.06.2019).

Elçi, Ş., Karataylı, i. (2008). İnovasyon Rehberi; Karlıık ve Rekabetin El Kitabı. ANSiAD, http://www.ansiad.org.tr/upload/2017020813054488-inovasyon.pdf, (ET: 24.06.2019).

Hürriyet, Dünya'da e-ticaret hacmi 700 milyar doları geçti, www.hurriyet.com.tr/amp/ekonomi/dunyada-e-ticaret-hacmi-700milyar-dolarigecti-41033624, (ET: 26.06.2019).

Kalaycı, C. (2008). Elektronik Ticaret ve KOBi'lere Etkileri. Uluslararası Iktisadi ve Idari İncelemeler Dergisi, 1 (1), s. 139-150.

Pırnar, i. (2005). Turizm Endüstrisinde E-Ticaret. Bolu Abant İzzet Baysal Üniversitesi, îktisadi ve İdari Bilimler Fakültesi Ekonomik ve Sosyal Araştırmalar Dergisi, 1, s. 28-55.

inovaloji.com, https://www.inovaloji.com/, (ET: 24.06.2019).

gittigidiyor.com , https://www.gittigidiyor.com/hakkimizda., (ET: 24.06.2019). 